\title{
Microstructure and hydraulic properties of biological soil crusts on sand dunes: a comparison between arid and temperate climates
}

T. Fischer ${ }^{1}$, A. Yair ${ }^{2}$, and M. Veste ${ }^{3}$

${ }^{1}$ Central Analytical Laboratory, Brandenburg University of Technology, Cottbus, Germany

${ }^{2}$ Department of Physical Geography, Hebrew University Jerusalem, Israel

${ }^{3}$ Centre for Energy Technology Brandenburg e.V., Cottbus, Germany

Received: 28 July 2012 - Accepted: 25 Augsut 2012 - Published: 18 September 2012

Correspondence to: T. Fischer (thomas.fischer@tu-cottbus.de)

Published by Copernicus Publications on behalf of the European Geosciences Union.

Microstructure and hydraulic properties of biological soil crusts

T. Fischer et al.

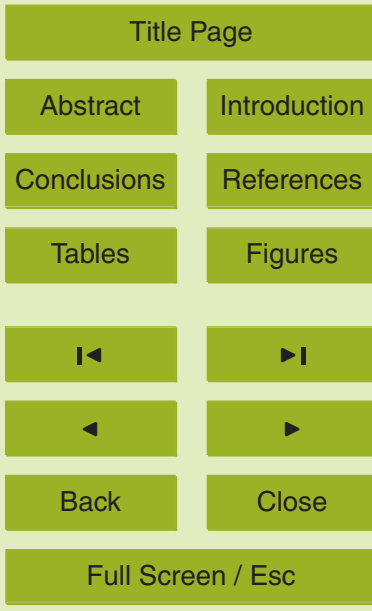

Printer-friendly Version 


\section{Abstract}

We studied the relationships between crust microstructure, infiltration and water holding capacity under arid and temperate conditions (Factor A: Climate) on biological soil crusts (BSCs) sampled along a catena on mobile sand dunes (Factor B: 5 Catena). The arid study site was located near Nizzana, Israel (precipitation: $86 \mathrm{mma}^{-1}$, PET: $\sim 2500 \mathrm{mma}^{-1}$ ) and the temperate site near Lieberose, Germany (precipitation: $569 \mathrm{mma}^{-1}$, PET: $\sim 780 \mathrm{mma}^{-1}$ ). BSCs were sampled near the dune crest, at the centre of the dune slope and at the dune base at each site. Scanning electron microscopy (SEM) was used to characterize BSC morphology and microstructure. Infiltration was determined using microinfiltrometry under controlled moisture conditions in the lab. Water holding capacities were determined after water saturation of the dry BSCs. Wettability of the crusts was characterized using a "repellency index", which was calculated from water and ethanol sorptivities. Irrespective of the climate, an accumulation of fine particles in the BSCs was found, increasing along the catena from dune crest to dune base. Texture was finer and water holding capacities of the underlying substrate were higher at the arid site, whereas surface wettability was reduced at the temperate site. At both sites, BSCs caused extra water holding capacity compared to the substrate. Infiltration rates decreased along the catena and were generally lower at the dune slope and base of the arid site. A mechanism of crust stabilization is proposed where BSCs benefit from increased texture and biomass mediated water supply, and where the water supply to higher plants was limited due to alteration of physico-chemical surface properties under temperate conditions.

\section{Introduction}

Sand dunes occur worldwide under all climatic conditions. These ecosystems are stressful habitats for higher plants, as nutrients and water are often limiting factors for their growth. Mobile sand dunes can be regarded as initial ecosystems with a sparse

\section{BGD}

9, 12711-12734, 2012

Microstructure and hydraulic properties of biological soil crusts

T. Fischer et al.

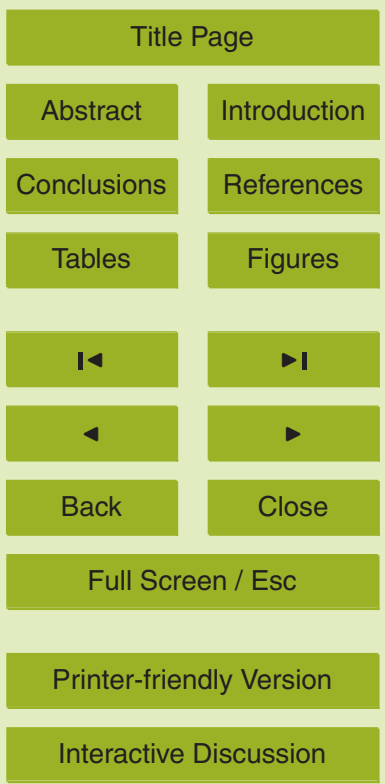


cover of vascular vegetation. The first millimetres of the top soil surface is often covered by cryptogames forming a biological soil crust (BSC). These surface crusts are assemblages of cyanobacteria, green algae, mosses, liverworts, fungi, soil lichens as well as soil bacteria (Belnap and Lange, 2001). As first colonizers, these cryptogames play

5 a key-role for the functioning of various ecosystems at initial stages of development (Veste et al., 2001b; Cutler et al., 2008; Bowker et al., 2010; Brankatschk et al., 2012). Containing photosynthetically active organisms, they risk extinction through shading by canopies of higher vegetation or by litter fall during ecosystem succession. However, unlike higher vegetation, microphytes residing in BSCs are able to recover from dor10 mancy after periods of extreme drought due to their poikilohydric nature. BSCs can benefit from this advantage and achieve ecological stability by redirecting water which can be used by their competitors (Fischer et al., 2012a), thereby contributing to the formation of vegetation patterns that follow geomorphological structures such as water run-on depressions, dune bases etc. (Yair et al., 2011). The mechanism of redirecting 15 water has been reported to consist of the following components: (I) physico-chemical surface properties such as water repellency or inhibited wettability, (II) slow water infiltration (Yair, 1990; Kidron et al., 1999; Fischer et al., 2010), both generating run-off, and (III) water storage by the BSCs, which may reduce water infiltration into the rooting zone of vascular plants (Ram and Aaron, 2007), thereby also defeating competitors.

The hydrological effects of biological soil crusts and their development under different climatic conditions and microstructures are crucial for understanding the role of BSCs for ecosystem development (Schaaf et al., 2011). Therefore, the aim of this study was to test the hypothesis that BSCs possess a mechanism of self-stabilization through water redirection under various environmental conditions. To address this aim, we hypothesize that the three components mentioned above contribute to different degrees, depending on the geological substrate, on the climate, and on the development of the BSCs, like BSC thickness, species composition and diversity, or physical crusting. Based on these considerations, we investigated the relationship between crust microstructure, infiltration and water holding capacity under arid and temperate conditions

BGD

9, 12711-12734, 2012

Microstructure and hydraulic properties of biological soil crusts

T. Fischer et al.

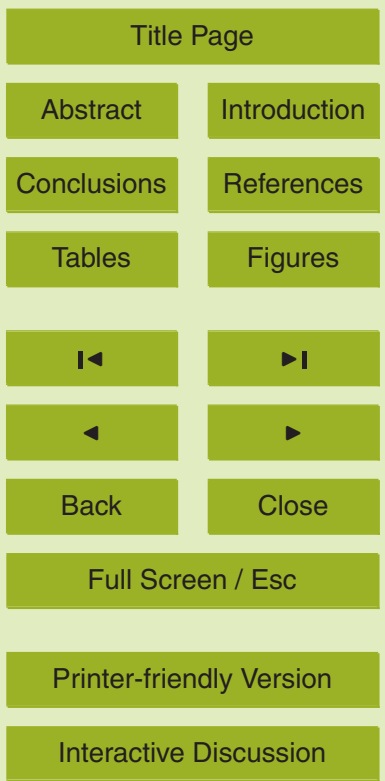


(Factor A: Climate) on BSCs sampled along a catena on mobile sand dunes (Factor B: Catena).

BGD

9, 12711-12734, 2012

\section{Material and methods}

\subsection{Study sites and sampling}

5 The temperate sampling site was located near Lieberose, Brandenburg, North-east Germany $\left(51^{\circ} 55^{\prime} 49^{\prime \prime} \mathrm{N}, 14^{\circ} 22^{\prime} 22^{\prime \prime} \mathrm{E}\right.$, Fig. 1). The climate is temperate continental with an average rainfall of $569 \mathrm{mma}^{-1}$, with an average potential evapotranspiration of $\sim 780 \mathrm{mma}^{-1}$, and with an average annual temperature of $8.9^{\circ} \mathrm{C}$. Due to disturbances by former military activities, the sand dunes are partly mobile at the dune crest.

10 Undisturbed samples of biological soil crusts were collected in 2 replicates by gently "coring" the surface with $10 \mathrm{~cm}$ diameter petri dishes and carefully padded with cotton wool to avoid rupture near the crest, at the slope and at the base of a carbonate-free, siliceous east-facing dune in May 2010 and in July 2011. The samples were cut into subsamples for the subsequent micro-structural and hydrological measurements. The vegetation was dry acidic grassland with tussocks of Corynephorus canescens. A detailed description of the site was given by Fischer et al. (2010). The dominating species were the green algae Zygogonium ericetorum and Klebsormidium crenulatum as well as the moss Polytrichum piliferum (Fischer et al., 2012b). The texture of the substrate did not differ significantly between the sampling points and was classified as medium sand with $20 \pm 10 \%$ coarse sand $(630-2000 \mu \mathrm{m}), 59 \pm 3 \%$ medium sand $(200-630 \mu \mathrm{m})$, $17 \pm 3 \%$ fine sand $(63-200 \mu \mathrm{m})$, and less than $4 \%$ of particles below $63 \mu \mathrm{m}$ in diameter (Brankatschk et al., 2012).

The arid sand dunes of the North-Western Negev are part of the Sinai-Negev sand fields. The arid sampling site is located near Nizzana, Israel $\left(30^{\circ} 56^{\prime} 26^{\prime \prime} \mathrm{N}, 34^{\circ} 23^{\prime} 18^{\prime \prime} \mathrm{E}\right.$, 25 Fig. 2). It is characterized by linear dunes. The climate is arid with an average rainfall of $86 \mathrm{mma}^{-1}$, with an average potential evapotranspiration of $\sim 2500 \mathrm{mma}^{-1}$, and with an
Microstructure and hydraulic properties of biological soil crusts

T. Fischer et al.

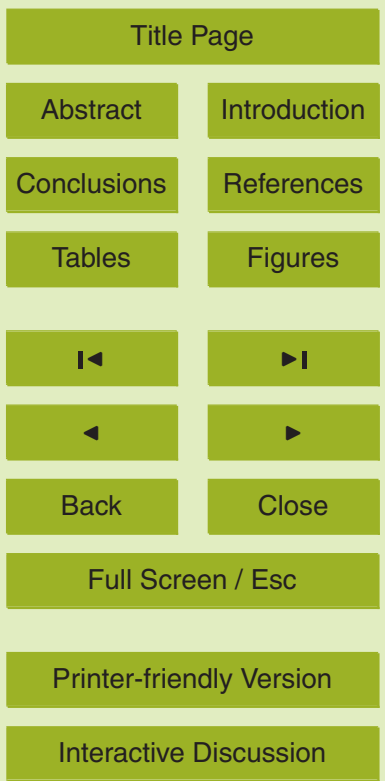


average annual temperature of $19.2^{\circ} \mathrm{C}$. Undisturbed samples of biological soil crusts were collected in 2 replicates ( 1 replicate only available for the dune base) by gently "coring" the surface with $10 \mathrm{~cm}$ diameter petri-dishes and carefully padded with cotton wool to avoid rupture near the crest, at the slope and at the base of a carbonatecontaining, siliceous north facing dune in September 2009. The samples were cut into subsamples for the subsequent micro-structural and hydrological measurements. The vegetation at the study site is dominated by various dwarf shrubs and shrubs (e.g. Anabasis articulata, Cornulaca monacantha, Lycium schweinfurthii, Moltkiopsis ciliata, Noaea mucronata) and annuals (Veste et al., 2011). The BSC species community was more diverse in Nizzana than in Lieberose, where the cyanobacteria Microcoleus sp., Trichocoleus sociatus, Scytonema sp., Nostoc sp., Phormidium sp., Oscillatoria sp., the green algae Macrochloris multinucleata and the mosses Tortula sp. and Bryum sp. were reported to be most frequent (Büdel and Veste, 2008). A comprehensive description of the study site was given by Breckle et al. (2008). The texture of the substrate 15 did not differ significantly along the catena and was classified as light loamy sand with less than $0.5 \%$ coarse sand $(630-2000 \mu \mathrm{m})$ at all sampling points, $16 \pm 3 \%, 29 \pm 12 \%$ and $25 \pm 3 \%$ medium sand $(200-630 \mu \mathrm{m})$ as well as $64 \pm 2 \%, 56 \pm 7 \%$ and $54 \pm 4 \%$ fine sand $(63-200 \mu \mathrm{m})$ near the dune crest, at the dune slope and at the dune base, respectively. The content of particles below $63 \mu \mathrm{m}$ amounted to $17 \pm 1 \%, 14 \pm 3 \%$ and $25 \pm 3 \%$ near the dune crest, at the dune slope and at the dune base, respectively.

Area related chlorophyll concentrations were determined after sample grinding and exhaustive extraction with $80 \%$ Acetone p.a. in the dark using the dichromatic method (Fischer et al., 2010).

\subsection{Micro-imaging}

25 Top view micro-images of undisturbed subsamples (see Sect. 2.1 "Study sites and sampling") were recorded using scanning electron microscopy (SEM) in 5 replicates. In order to record undisturbed vertical profiles of the crusts, the slope and base samples were embedded into low viscosity resin, cut vertically and polished in 5 replicates. The
BGD

$9,12711-12734,2012$

Microstructure and hydraulic properties of biological soil crusts

T. Fischer et al.

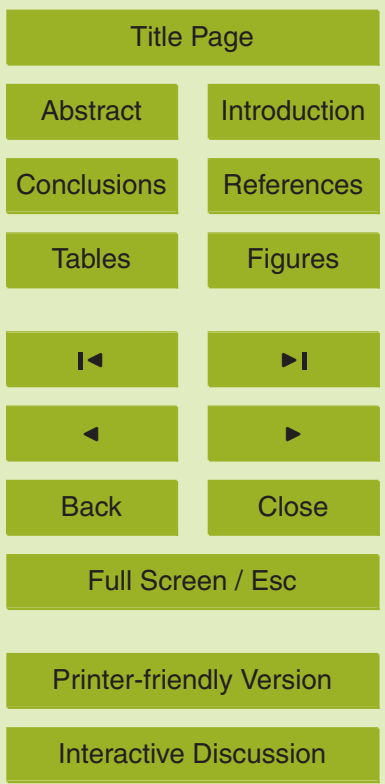


near crest samples were too fragile at both sites to resist this preparation procedure and had to be excluded from the vertical profiling. Back scattered electron detection (BSD) after sputtering with gold was used for all SEM recordings.

The vertical profiles were subdivided into upper BSC, lower BSC and adhering min5 eral substrate. Image analysis of the vertical profiles included the setting of grey value thresholds to separate mineral particles from organic structures and respective binarization. Consecutive pixel erosion and dilatation were used to separate mineral particles from each other, followed by micro-scale particle size classification. The classes were selected according to the German soil mapping guide (Ad Hoc AG Boden, 2005) 10 using EsiVision pro 3.2 (Soft Imaging System GmbH, Germany). Due to an SEM pixel resolution of $\sim 5 \mu \mathrm{m}$ fine silt and clay particles were not distinguishable as particles in the SEM micro-images, and therefore excluded from image analysis.

\subsection{Hydrology}

The water drop penetration time test (WDPT-test, Adams et al., 1969), which is often used to characterize water repellency, was not applicable in this study, because drop penetration was too rapid on all crusts. Instead, we assessed hydrophobic surface properties by determination of a "repellency index" $R_{i}$, as proposed by Fischer et al. (2010), which is more a measure of surface (un)polarity during wetting rather than an indicator of strong hydrophobicity like the WDPT-test. The theoretical value of 201 characterizes totally non-repellent soils (Hallet and Young, 1999). The index exceeds 50 for highly repellent soils (Urbanek et al., 2007). Steady state ethanol and water flows $\mathrm{Q}_{(-2)}$ (in $\mathrm{mg} \mathrm{s}^{-1}$ ) through the undisturbed samples were determined using a microinfiltrometer (Hallet and Young, 1999). The subscript -2 signifies the pressure head in $\mathrm{cm}$ at which the measurements were made. High values of the repellency index indicate low surface polarity/wettability. Infiltration measurements were performed in 10 replicates.

After measuring infiltration through the dry surface of the samples, the microbial mucilage was allowed to swell. Measurements were stopped after $75 \mathrm{~s}$ and repeated

\section{BGD}

9, 12711-12734, 2012

Microstructure and hydraulic properties of biological soil crusts

T. Fischer et al.

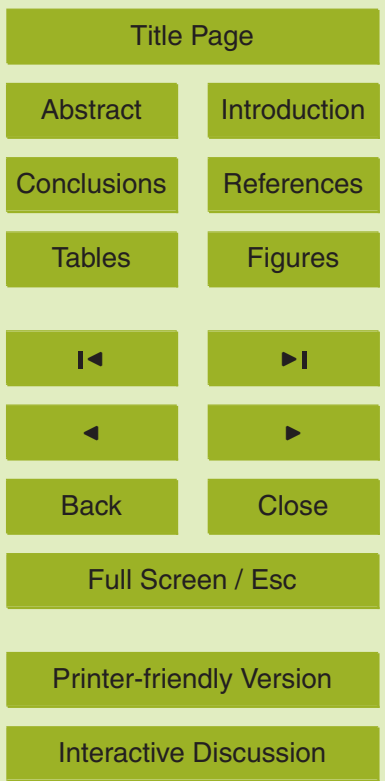


for $75 \mathrm{~s}$ after $300,600,1200$ and $1800 \mathrm{~s}$ (Fischer et al., 2010). Infiltration kinetics was determined in 4 replicates.

Water holding capacities (WHC) of the undisturbed topsoil were determined after water saturation in a sand bed (suction pressure $-60 \mathrm{hPa}, \mathrm{pF}=1.8$, Eijkelkamp appa5 ratus, The Netherlands) using $8.13 \mathrm{~cm}^{3}(11.5 \mathrm{~mm}$ deep, diameter $30.0 \mathrm{~mm})$ steel rings. After reaching constant weight at $-60 \mathrm{hPa}$, the samples were dried to constant weight at $105^{\circ} \mathrm{C}$, which was considered to be absolute dryness. The mineral substrate was used as a control. The water holding capacities were determined in 3 replicates.

\subsection{Statistical analysis}

10 Particle size distributions were compared using the $\chi^{2}$-Test. Pairwise $t$-Tests, or ANOVA followed by Tukeys HSD-Test were performed for comparison of arithmetic mean values after passing the Shapiro-Wilk-Test for normality of distribution and the Levene-test for homogeneity of variance, otherwise the Kruskall-Wallis $\mathrm{H}$-Test and the multiple Behrens-Fisher-Test were preferred.

\section{$15 \quad 3$ Results}

At both sites, near the dune crest the soil surface was dominated by sand grains that were slightly physically stabilized by few organic filamentous elements. The particles were finer at Nizzana (Fig. 3a, b). In the samples from the dune slope at Lieberose, algal filaments partially filled the matrix pores and enmeshed sand grains. In addition to organic structures, mineral fine material accumulated between biogenic crust elements at Nizzana (Fig. 3c, d). The BSC samples from the dune base were characterized by intense growth of crust organisms, again with additional accumulation of mineral fine material at Nizzana (Fig. 3e, f).

The particle size distribution was shifted towards coarser fractions in the image anal-

BGD

9, 12711-12734, 2012

Microstructure and hydraulic properties of biological soil crusts

T. Fischer et al.

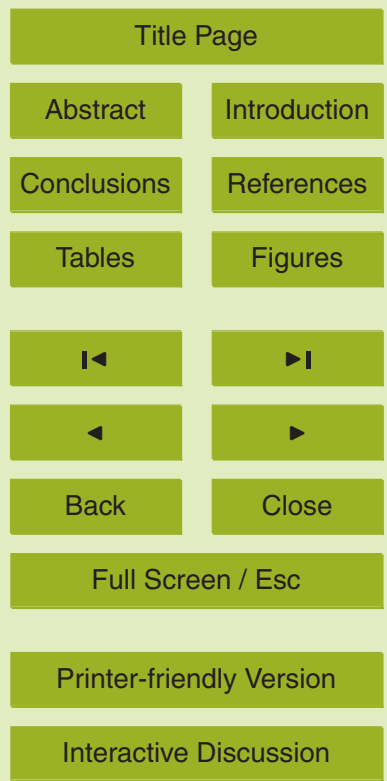


organic matter were not removed prior to crust embedding. Consequently, intact microaggregates may have been recognized as single particles during image analysis. (II) Fine silt and clay particles had to be excluded from particle size analysis due to an SEM image pixel resolution of $\sim 5 \mu \mathrm{m}$ (see Sect. 2.2).

5 Micro-scale particle size image analysis of the BSC profiles at the dune slopes revealed that there is no statistical evidence of micro-stratification at the dune slopes at both sites. While the texture tended to be finer in the lower BSC in Lieberose $\left(\chi^{2}\right.$-test, $p=0.38$ ), no within-crust micro-stratification could be observed in Nizzana. At both dune bases an accumulation of finer particles near the surface was detected, where 10 the highest amount was observed in the lower BSCs at both sites. While the mineral substrate and the crust were dominated by medium sand in Lieberose, substrate and crust in Nizzana were dominated by fine and medium sand, as well as by coarse silt and fine sand, respectively (Figs. 4 and 5). At the dune base in Lieberose, the particle size distribution of the upper BSC differed significantly from the lower BSC and 15 the substrate ( $\chi^{2}$-test, $p<0.01$ and $p=0.04$, respectively), whereas lower BSC and substrate did not differ significantly $\left(\chi^{2}\right.$-test, $\left.p=0.06\right)$. At the dune base in Nizzana, the particle size distribution of the upper and lower BSC differed significantly from the substrate $\left(\chi^{2}\right.$-test, $\left.p<0.01\right)$. The lower BSC did not differ significantly from the upper BSC $\left(\chi^{2}\right.$-test, $\left.p=0.06\right)$.

20 Infiltration rates decreased along both catenas, but were higher at the dune slope and base in Lieberose than in Nizzana (Fig. 6). Infiltration did not follow a trend over time near the dune crest at both sites $(p=0.41$ and 0.63 in Lieberose and Nizzana, respectively). Infiltration rates were reduced significantly within the first 10 min after rewetting at the dune slope ( $t$-test, $p=0.01)$ and base $(p=0.03)$ in Lieberose, where

25 a similar, but non-significant trend $(p=0.09)$ was observed at the dune slope in Nizzana. After reaching their maximum at the dune slopes and bases at both sites after $10 \mathrm{~min}$, infiltration rates dropped continuously with time with one exception: At the dune base in Nizzana infiltration was highest at the onset of rewetting, followed by an exponential decrease with time $\left(y=2.3 \exp (-0.0022 \mathrm{t})+1.3, r^{2}=0.63, p=0.03\right)$.

\section{BGD}

$9,12711-12734,2012$

Microstructure and hydraulic properties of biological soil crusts

T. Fischer et al.

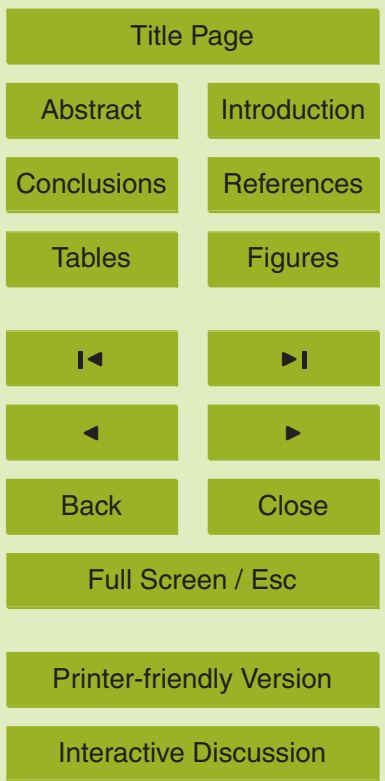


In Lieberose, surface polarity decreased along the catena from the non-crusted surface and the crust sampled near the dune crest to the dune slope, but increased at the dune base to values comparable with the dune crest. In Nizzana, surface polarity decreased along the catena at generally low levels of $R_{i}$, where the values for all BSCs 5 fall within the range of the mineral substrate in Lieberose (Fig. 7).

The water holding capacities of the underlying substrate at $\mathrm{pF}>1.8$ amounted to $9 \pm 3 \%$ and did not differ significantly along the catena in Lieberose, but decreased from $25 \pm 4 \%$ to $19 \pm 4 \%$ and increased to $33 \pm 5 \%$ from crest to slope and to base in Nizzana, respectively (Fig. 8). At both sites the BSCs added extra WHC to the topsoil, which was 10 more pronounced and increased along the catena in Lieberose. In Nizzana, the crust induced extra WHC was less pronounced than in Lieberose and increased from crest to slope, but decreased from slope to base (Fig. 9). The water holding capacities were significantly higher in Nizzana than in Lieberose $(t$-Test, $p<0.01)$.

\section{Discussion}

15 Because the sandy mineral substrate did not differ significantly between the sampling points in Lieberose, decreasing infiltration rates along the catena follow the pattern of BSC development. Decreasing along the catena infiltration in Nizzana may possibly be determined by both biotic elements and by accumulated fine material. However, decreasing infiltration $10 \mathrm{~min}$ after rewetting at the dune slope and base in Lieberose and at the dune slope in Nizzana, as well as immediately after rewetting at the dune base in Nizzana, point to clogging of matrix pores by swelling of microbial mucilage, thereby possibly promoting surface run-off at the dune slopes (Verrecchia et al., 1995; Yair, 2001) and reducing infiltration losses at the dune bases (Fig. 6).

Though surface polarity decreased slightly downslope in Nizzana, $R_{i}$ values for all BSCs fall within the range of the mineral substrate of Lieberose, which was characterized by immediate wetting. The dominating species in Lieberose, Zygogonium ericetorum, is known to form water repellent mats (Ettl and Gärtner, 1995) and may explain

\section{BGD}

9, 12711-12734, 2012

Microstructure and hydraulic properties of biological soil crusts

T. Fischer et al.

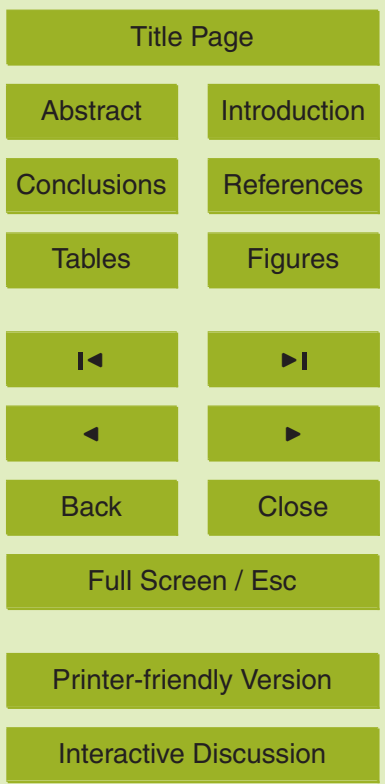


decreasing surface polarity with progressing surface cover. Along with frequent deposition of non-hydrophobic eolian sand at the dune base, which may bury water repellent surface algae, emerging mosses may cause lesser generation of hydrophobic surfaces, resulting in decreasing repellency indices (Fischer et al., 2010). The moss

5 Polytrichum piliferum is able to grow through an annual sand deposition layer of up to $2 \mathrm{~cm}$ (Ellenberg, 1996) and was reported to be frequent in the study area (Otte, 2002; Fischer et al., 2012b). The decrease of surface polarity along the catena is also reflected by impaired initial infiltration rates at the dune slope ( $t$-test, $p=0.08$ ) and base in Lieberose ( $t$-test, $p=0.03$ ), where maximum values were reached $10 \mathrm{~min}$ after the 0 onset of rewetting (Fig. 6).

Insignificant between the sampling points water holding capacities reflect the homogeneous along the catena substrate in Lieberose. In contrast, the substrates along the catena in Nizzana seem to have undergone erosional processes, resulting in an accumulation of fine colluvial material at the dune base. This was also reflected in an elevated water holding capacity (Fig. 8). The fine-grain material originated from local sources along the slope. Surface stability plays an important role for development of the structure of the soil crust here (Littmann and Gintz, 2000). Already at early stages of crust development, after complete crust removal a high percentage of silt and clay was found within the surface crust at the Nizzana site (Yair, 2008). However, deposition of fine-grain material - which might have contributed to the fine-grain material in the crust - is relatively low at the Nizzana site, and the spatial pattern of dust deposition does not coincide with the distribution of the BSCs within the dune field (Littmann, 1997). At both sites and all along the catenas, biological soil crusts added extra WHC to the topsoil, which further corresponded to crust biomasses reported earlier (Fig. 9).

Fine textured micro stratification layers formed in the crusts (Figs. 4 and 5) may act as infiltration barriers and as additional water reservoirs, providing more favourable conditions for the development of microphytes near the surface, and contribute to longer physiological activity after sunrise (Veste et al., 2001a, 2008). Besides differences in the topo-climatic conditions, resulting in longer shading on north-facing slopes (Veste

\section{BGD}

$9,12711-12734,2012$

Microstructure and hydraulic properties of biological soil crusts

T. Fischer et al.

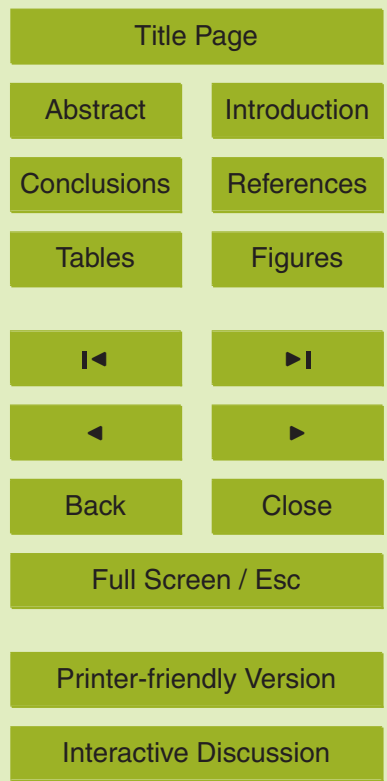


and Littmann, 2006), the water holding capacity is an important factor here (Fischer et al., 2012a). Ensuring better growth and survival of BSCs, it may be necessary for additional water supply to crust organisms under arid conditions, where higher plants are suppressed by low water availability. Furthermore, water infiltration into deeper soil 5 is limited by the biological soil crusts at low rainfall intensities. This was observed at the arid as well as the temperate site and has negative impacts on the water availability for the higher vegetation, as it could be shown for sand dunes of the Northern Negev (Yair et al., 2008). Under temperate conditions, however, better water availability exposes surface microphytes to the risk of replacement by higher vegetation during plant 10 succession. In particular, the formation of moss-dominated crusts limits the infiltration of water into deeper soil (Yair et al., 2008; Fischer et al., 2012a) at low rainfall amounts and intensity due to their high water holding capacity. It is hypothesized that only BSCs able to prevent usage of water by their competitors may stabilize under temperate conditions.

\section{Conclusions}

Both extracellular polymeric substances as well as fine texture are known to enhance the water holding capacity and to inhibit infiltration. Contrary to the dune at the temperate site, differences in substrate texture along the catena superimposed the influence of biotic elements on water holding capacities and on infiltration rates at the arid site. 20 Finer texture generally caused higher water holding capacities under arid conditions, which is a necessary condition for BSC growth and survival. In addition, substrate wettability was reduced under temperate conditions, most likely due to the dominating species Zygogonium ericetorum, which is knows to form water repellent mats. It was hypothesized that BSCs stabilized through enhanced water supply to crust organisms,

\section{BGD}

$9,12711-12734,2012$

Microstructure and hydraulic properties of biological soil crusts

T. Fischer et al.

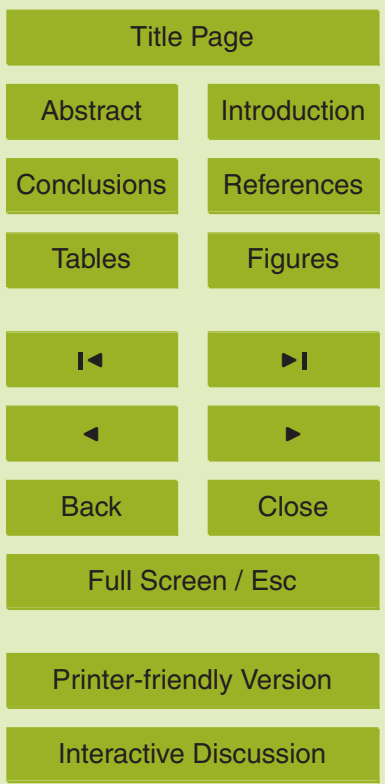


Acknowledgements. This study is part of the Transregional Collaborative Research Centre 38 (SFB/TR 38), which is financially supported by the Deutsche Forschungsgemeinschaft (DFG, Bonn) and the Brandenburg Ministry of Science, Research and Culture (MWFK, Potsdam). The authors thank Rainer Schulin (ETH Zürich) for his critical review of the manuscript, and 5 Wolfgang Wiehe and Philipp Lange (BTU Cottbus) for technical assistance.

\section{References}

Ad Hoc AG Boden: Bodenkundliche Kartieranleitung, 5. Aufl., Bundesanstalt für Geowissenschaften und Rohstoffe und Niedersächsisches Landesamt für Bodenforschung, Schweizerbart, Stuttgart, 2005.

Adams, S., Strain, B. R., and Adams, M. S.: Water-repellent soils and annual plant cover in a desert scrub community of Southeastern California, in: Proc. Symp. on Water Repellent Soils, University of California, Riverside, 6-10 May 1968, 289-296, 1969.

Belnap, J. and Lange, O. L. (Eds.): Biological Soil Crusts: Structure, Function and Management, Ecol. Studies 150, Springer Publisher, Heidelberg-Berlin-New York, 2001.

15 Bowker, M. A., Maestre, F. T., and Escolar, C.: Biological crusts as a model system for examining the biodiversity - ecosystem function relationship in soils, Soil Biol. Biochem., 42, 405-417, 2010.

Brankatschk, R., Fischer, T., Veste, M., and Zeyer, J.: Succession of $\mathrm{N}$ cycling processes in biological soil crusts on a Central European inland dune, FEMS Microbiol. Ecol., in press, doi:10.1111/j.1574-6941.2012.01459.x, 2012.

Breckle, S.-W., Yair, A., and Veste, M. (Eds.): Arid Dune Ecosystems - The Nizzana Sands in the Negev-Desert, Ecological Studies Vol. 200, Springer, Berlin Heidelberg New York, 2008.

Büdel, B. and Veste, M.: Biological crusts, in: Arid Dune Ecosystems - The Nizzana Sands in the Negev Desert, edited by: Breckle, S.-W., Yair, A., and Veste, M., Ecological Studies 200, $25 \quad$ Springer, Berlin Heidelberg New York, 2008.

Cutler, N. A., Belyea, L. R., and Dugmore, A. J.: The spatio-temporal dynamics of primary succession, J. Ecol., 96, 231-246, 2008.

Ellenberg, H.: Vegetation Mitteleuropas mit den Alpen in ökologischer und historischer Sicht, Ulmer, Stuttgart, 1996.
Ettl, H. and Gärtner, G.: Syllabus der Boden-, Luft- und Flechtenalgen, Fischer, Stuttgart, 1995.

\section{BGD}

$9,12711-12734,2012$

\section{Microstructure and hydraulic properties of biological soil crusts}

T. Fischer et al.

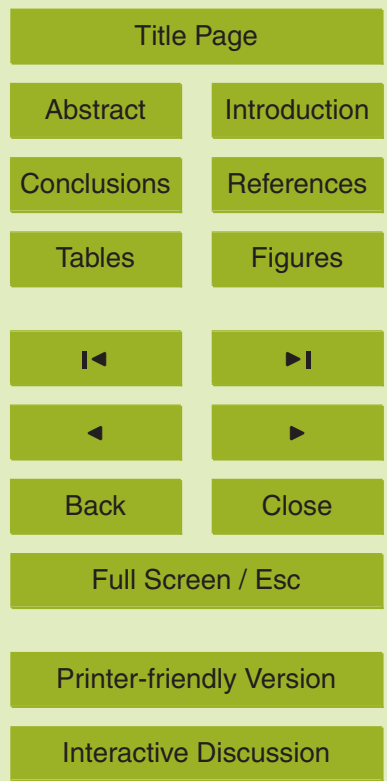


Fischer, T., Veste, M., Wiehe, W., and Lange, P.: Water repellency and pore clogging at early successional stages of microbiotic crusts on inland dunes, Brandenburg, NE Germany, Catena, 80, 47-52, 2010.

Fischer, T., Veste, M., Bens, O., and Hüttl, R. F.: Dew formation on the surface of biological 5 soil crusts in central European sand ecosystems, Biogeosciences Discuss., 9, 8075-8092, doi:10.5194/bgd-9-8075-2012, 2012a.

Fischer, T., Veste, M., Eisele, A., Bens, O., Spyra, W., and Hüttl, R. F.: Small scale spatial heterogeneity of Normalized Difference Vegetation Indices (NDVI) and hot spots of photosynthesis in biological soil crusts, Flora, 207, 159-167, 2012b.

10 Hallet, P. D. and Young, I. M.: Changes to water repellence of soil aggregates caused by substrate-induced microbial activity, Eur. J. Soil Sci., 50, 35-40, 1999.

Kidron, G. J., Yaalon, D. H., and Vonshak, A.: Two causes for runoff initiation on microbiotic crusts: hydrophobicity and pore clogging, Soil Sci., 164, 18-27, 1999.

Littmann, T.: Atmospheric input of dust and nitrogen into the Nizzana sand dune ecosystem,

$15 \quad$ North-Western Negev, Israel, J. Arid Environ., 36, 433-457, 1997.

Littmann, T. and Gintz, D.: Eolian transport and deposition in a partially vegetated linear sand dune area (Northwestern Negev, Israel), Z. Geomorphol., Supplement Band 121, 77-90, 2000.

Otte, V.: Untersuchungen zur Moos- und Flechtenvegetation der Niederlausitz, Ein Beitrag zur Bioindikation, Peckiana, 2, 1-340, 2002.

Ram, A. and Aaron, Y.: Negative and positive effects of topsoil biological crusts on water availability along a rainfall gradient in a sandy and area, Catena, 70, 437-442, 2007.

Schaaf, W., Bens, B., Fischer, A., Gerke, H. H., Gerwin, W., Grünewald, U., Holländer, H. M., Kögel-Knabner, I., Mutz, M., Schloter, M., Schulin, R., Veste, M., Winter, S., and Hüttl, R. F.: Patterns and processes of initial terrestrial-ecosystem development, J. Plant Nutr. Soil Sc., 174, 229-239, 2011.

Urbanek, E., Hallett, P., Feeney, D., and Horn, R.: Water repellency and distribution of hydrophilic and hydrophobic compounds in soil aggregates from different tillage systems, Geoderma, 140, 147-155, 2007.

30 Verrecchia, E., Yair, A., Kidron, K., and Verrecchia, K.: Physical properties of the psammophile cryptogamic crust and their consequences to the water regime of sandy soils. Northwestern Negev desert, Israel, J. Arid Environ., 29, 427-437, 1995.

\section{BGD}

$9,12711-12734,2012$

\section{Microstructure and hydraulic properties of biological soil crusts}

T. Fischer et al.

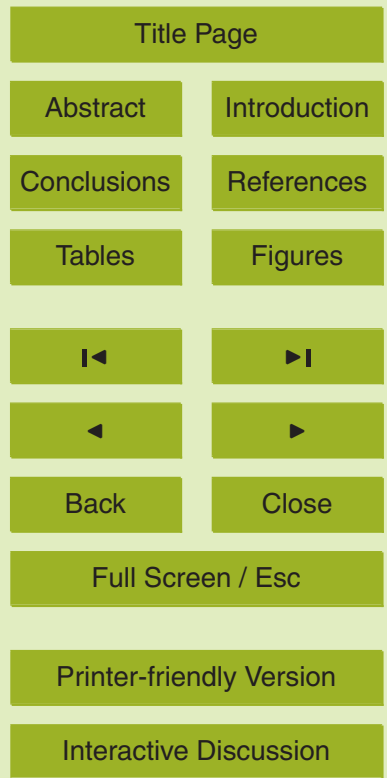


Veste, M., Littmann, T., Friedrich, H., and Breckle, S.-W.: Microclimatic boundary conditions for activity of soil lichen crusts in sand dunes of the North-Western Negev desert, Israel, Flora, 196, 465-476, 2001a.

Veste, M., Littmann, T., Breckle S.-W., and Yair A.: The role of biological soil crusts on desert sand dunes of the North-Western Negev (Israel), in: Sustainable Land-Use in Deserts, edited by: Breckle, S.-W., Veste, M., and Wucherer, W., Springer, Heidelberg, New York, Tokyo, $2001 b$.

Veste, M. and Littmann, T.: Dewfall and its geo-ecological implication for biological surface crusts in desert sand dunes (North-Western Negev, Israel), Journal of Arid Land Studies, 16, 139-147, 2006.

Veste, M., Heusinkveld, B. G., Berkowicz, S. M., Breckle, S.-W., Littmann, T., and Jacobs, A. F. G.: Dew formation and biological crusts activity, in: Arid Dune Ecosystems - The Nizzana Sands in the Negev Desert, edited by: Breckle, S.-W., Yair, A., Veste, M., Ecological Studies 200, Springer, Berlin Heidelberg New York, 305-318, 2008.

Veste, M., Breckle, S.-W., Eggert, K., and Littmann, T.: Vegetation pattern in arid sand dunes controlled by biological soil crusts along a climatic gradient in the Northern Negev desert, Basic and Applied Dryland Research, 5, 1-16, 2011.

Yair, A.: Runoff generation in a sandy area - the nizzana sands, Western Negev, Israel, Earth Surface Landforms, 15, 597-609, 1990.

20 Yair, A.: Effects of biological soil crusts on water redistribution in the Negev Desert, Israel: a case study in longitudinal dunes, in: Biological Soil Crusts: Structure, Function and Management, edited by: Belnap, J. and Lange, O. L., Ecological Studies 150, Springer Publisher, Heidelberg-Berlin-New York, 303-325, 2001.

Yair, A.: Succession stages in the recovery processes of the topsoil crust in a disturbed sandy arid area, in: Arid Dune Ecosystems - The Nizzana Sands in the Negev Desert, edited by: Breckle, S.-W., Yair, A., and Veste, M., Ecological Studies 200, Springer, Berlin Heidelberg New York, 285-303, 2008.

Yair, A., Veste, M., Almog, R., and Breckle, S.-W.: Sensitivity of a sandy area to climate change along a rainfall gradient at a desert fringe, in: Arid Dune Ecosystems - The Nizzana Sands 30 in the Negev Desert, edited by: Breckle, S.-W., Yair, A., and Veste, M., Ecological Studies 200, Springer, Berlin Heidelberg New York, 425-440, 2008.

\section{BGD}

9, 12711-12734, 2012

\section{Microstructure and hydraulic properties of biological soil crusts}

T. Fischer et al.

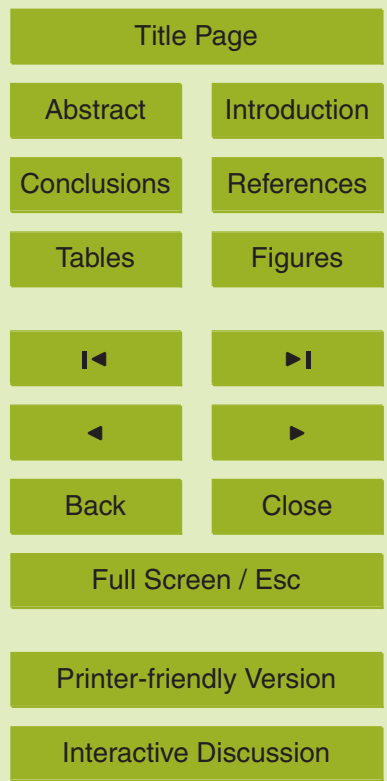


Yair, A., Almong, R., and Veste, M.: Differential hydrological response of biological topsoil crusts along a rainfall gradient in a sandy arid area: Northern Negev desert, Israel, Catena, 87, 326-333, 2011.

\section{BGD}

9, 12711-12734, 2012

Microstructure and

hydraulic properties of biological soil crusts

T. Fischer et al.

Title Page

Abstract Introduction

Conclusions

References

Tables

Figures

14

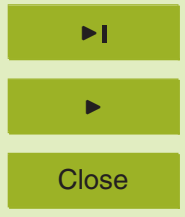

Back

Full Screen / Esc

Printer-friendly Version

Interactive Discussion 


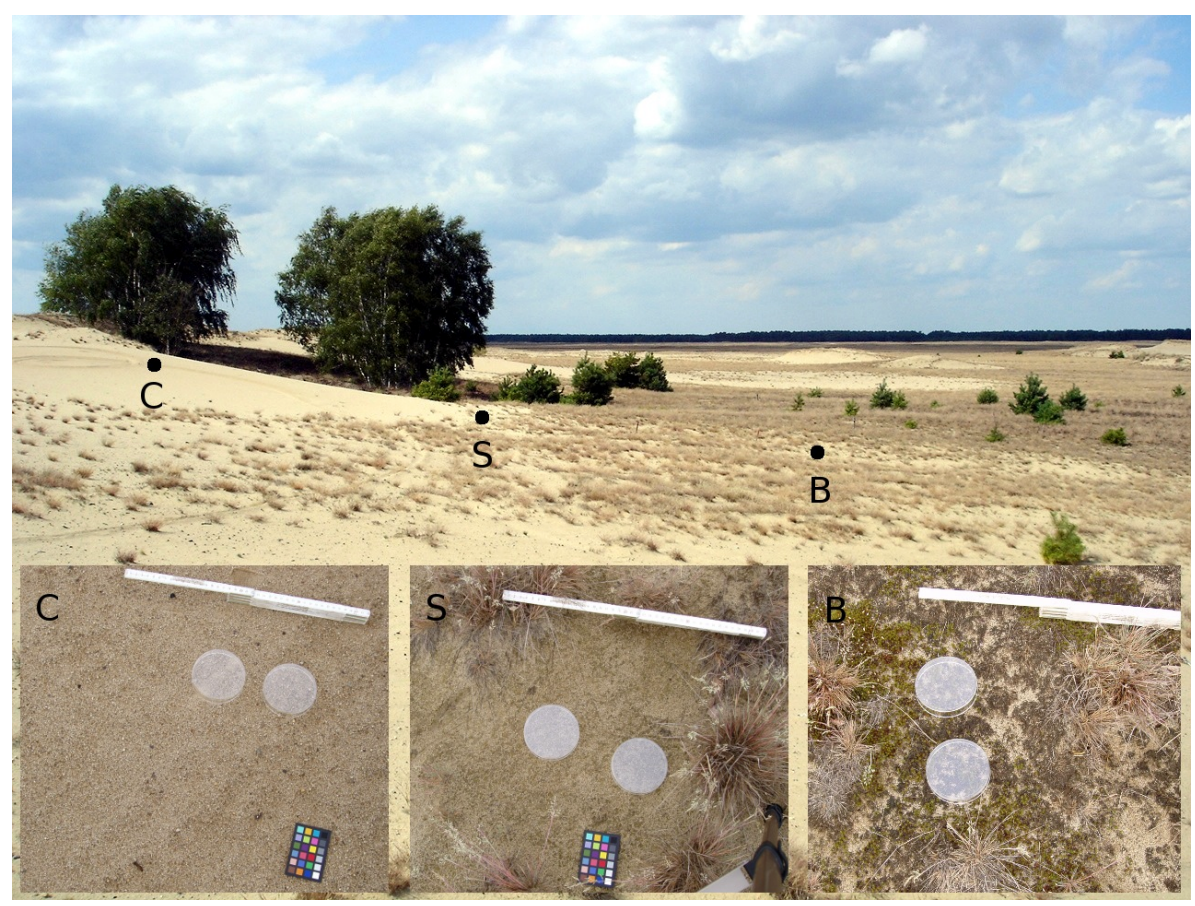

Fig. 1. Temperate sampling site at Lieberose, Germany, $C$ - near dune crest, $S$ - dune slope, B - dune base. Petri dishes placed on sampling points before gently "coring" the soil. The total distance between the sampling points was $15 \mathrm{~m}$.

\section{BGD}

$9,12711-12734,2012$

\section{Microstructure and hydraulic properties of biological soil crusts}

T. Fischer et al.

\section{Title Page}

\section{Abstract}

Introduction

Conclusions

References
Tables

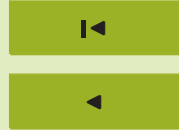

Back

\section{Figures}

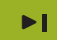

Close

\section{Full Screen / Esc}

Printer-friendly Version

Interactive Discussion 


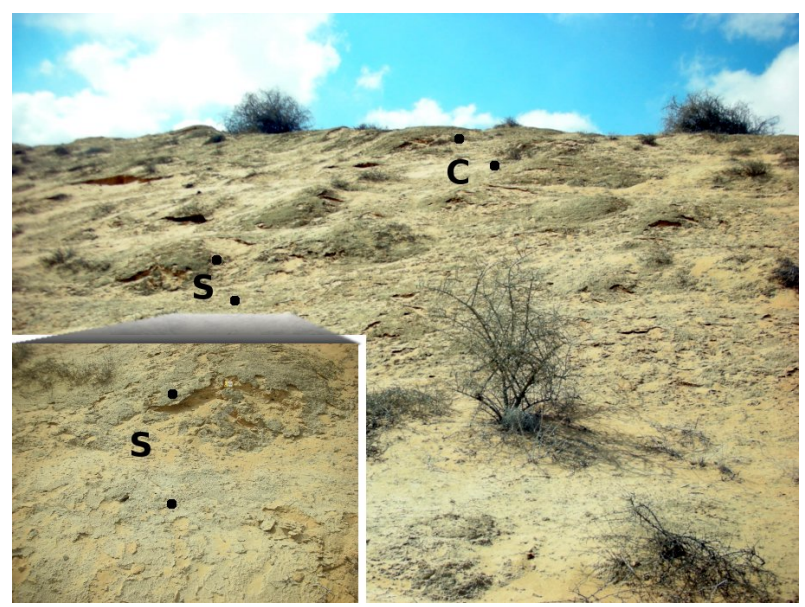

BGD

9, 12711-12734, 2012

\section{Microstructure and hydraulic properties of biological soil crusts}

T. Fischer et al.

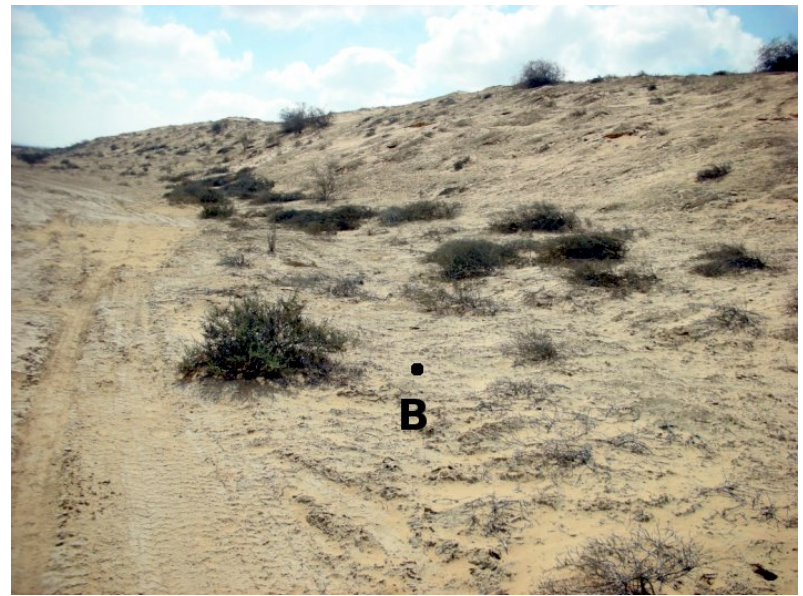

Title Page

\section{Abstract}

Conclusions

\section{Tables}

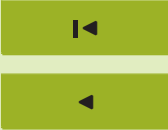

Back

Introduction

References

Figures
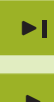

Close

Fig. 2. Arid sampling site at Nizzana, Israel, $\mathrm{C}$ - near dune crest, $\mathrm{S}$ - dune slope, $\mathrm{B}$ - dune base. The total distance between the sampling points was $7.4 \mathrm{~m}$.

\section{Full Screen / Esc}

Printer-friendly Version 


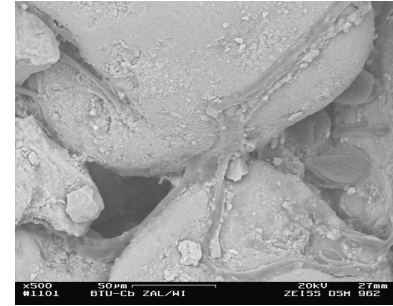

(a)

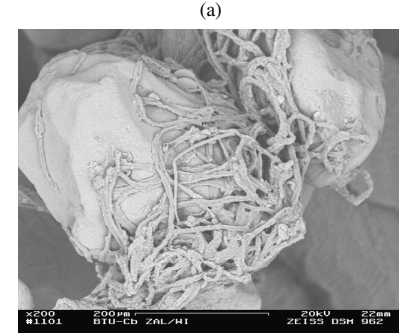

(c)

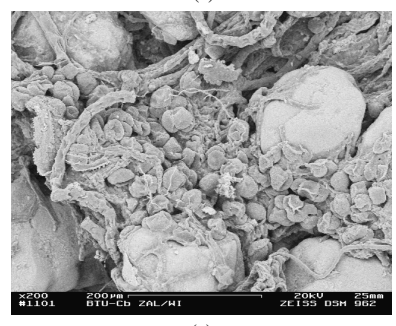

(e)

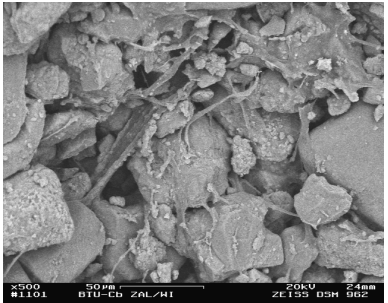

(b)
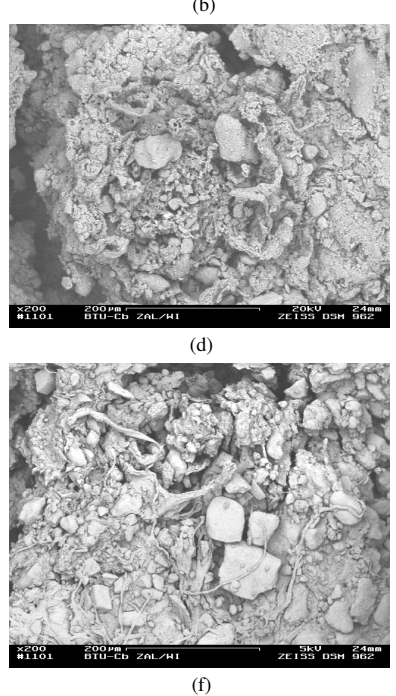

(f)

Fig. 3. Top view SEM micro-images of the BSCs near the dune crest $(\mathbf{a}, \mathbf{b})$, at the dune slope (c, d) and at the dune base (e, f) in Lieberose $(\mathbf{a}, \mathbf{c}, \mathbf{e})$ and Nizzana $(\mathbf{b}, \mathbf{d}, \mathbf{f})$, respectively.

\section{BGD}

9, 12711-12734, 2012

Microstructure and hydraulic properties of biological soil crusts

T. Fischer et al.

\section{Title Page}

\section{Abstract}

Introduction

Conclusions

References

Tables

Figures

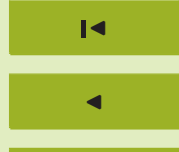

$\rightarrow$ I

Back

Close

\section{Full Screen / Esc}

Printer-friendly Version

Interactive Discussion 

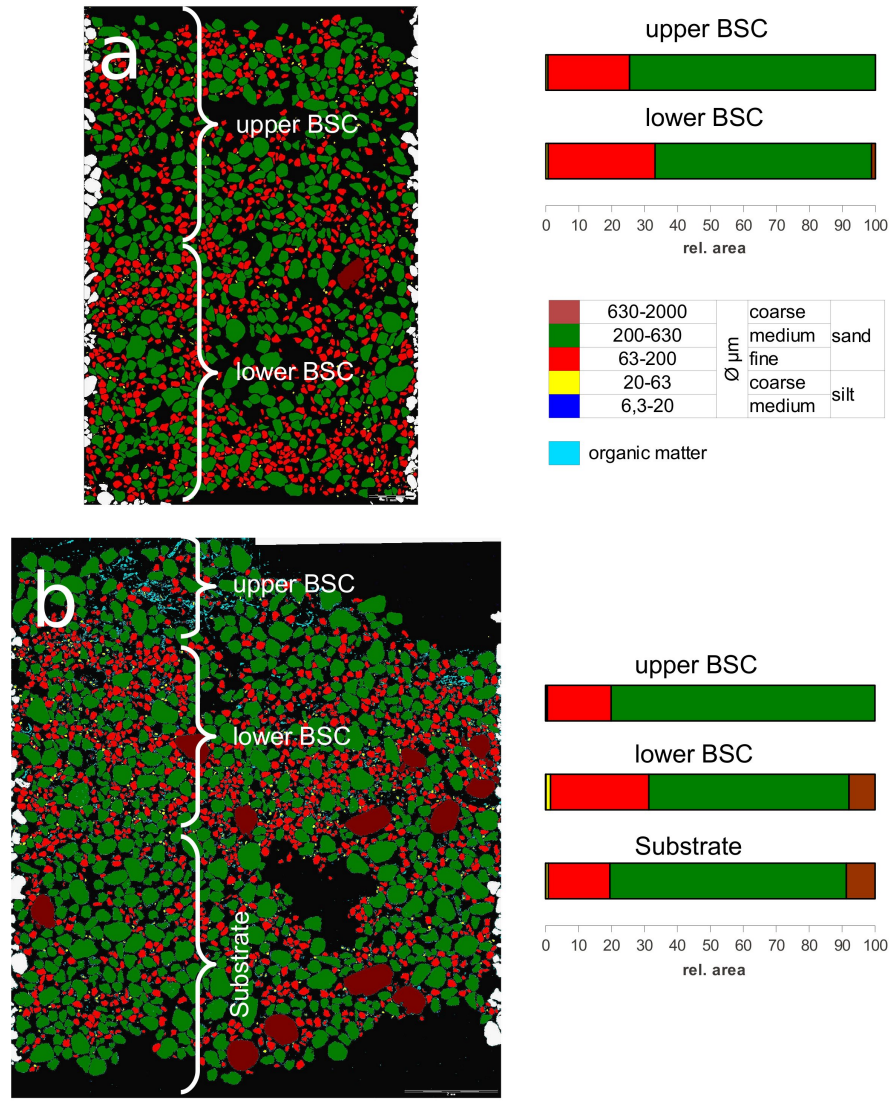

organic matter

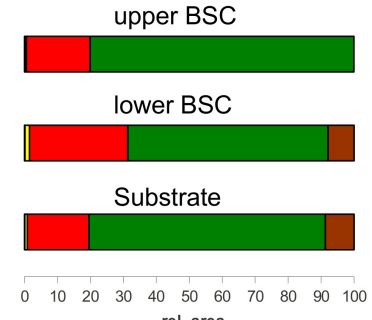

rel. area

Fig. 4. SEM micro-image of the vertical BSC profile at the dune base in Lieberose and particle size classification; (a) dune slope, (b) dune base.

\section{BGD}

9, 12711-12734, 2012

Microstructure and hydraulic properties of biological soil crusts

T. Fischer et al.

Title Page

Abstract

Introduction

Conclusions

References

Tables

Figures

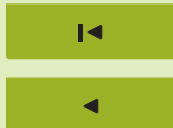

$\rightarrow$ I

Back

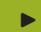

Close

Full Screen / Esc

Printer-friendly Version

Interactive Discussion 

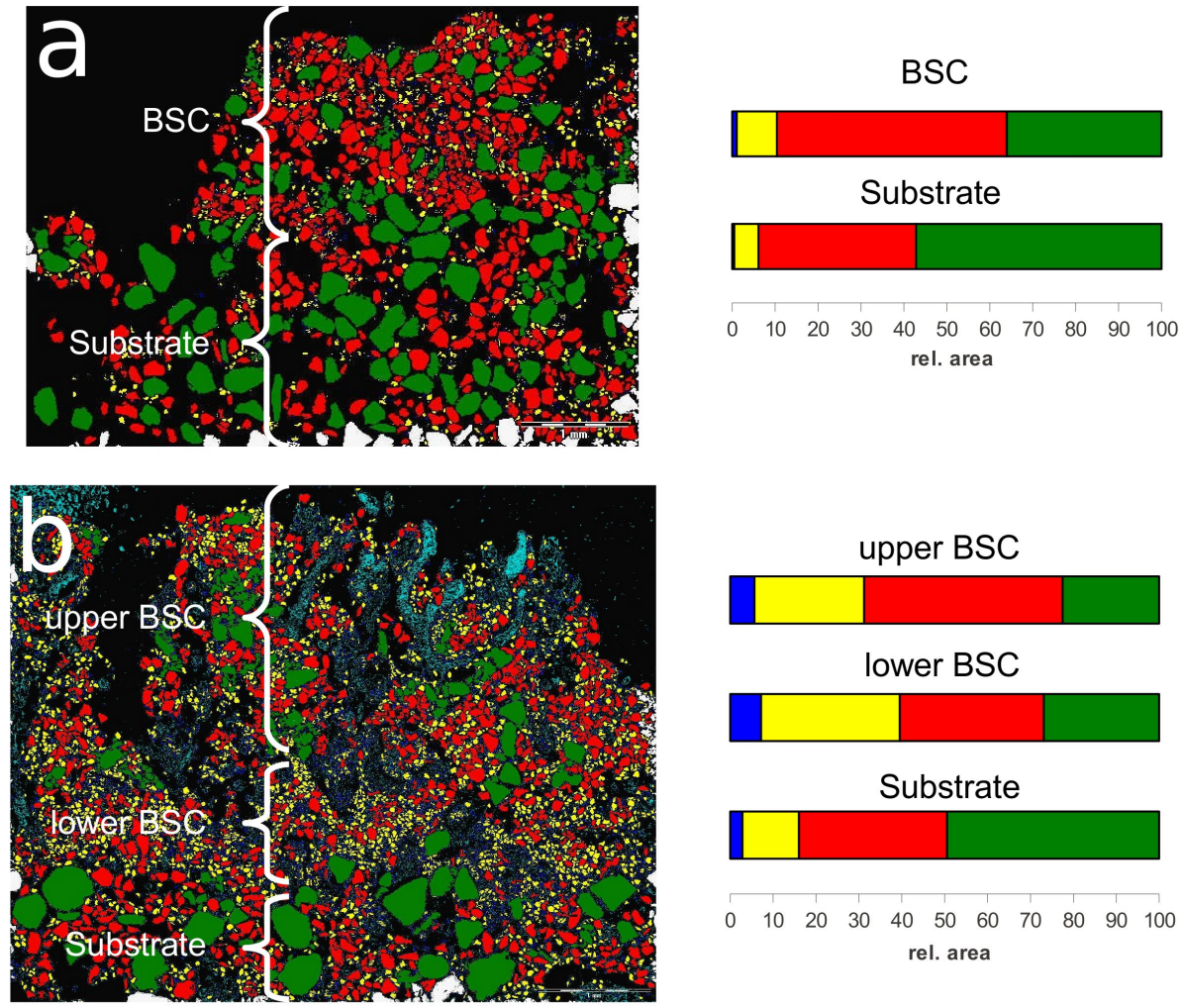

$\begin{array}{lllllllllll}0 & 10 & 20 & 30 & 40 & 50 & 60 & 70 & 80 & 90 & 100\end{array}$

rel. area

Fig. 5. SEM micro-image of the vertical BSC profile at the dune base in Nizzana and particle size classification; (a) dune slope, (b) dune base. For the legend see Fig. 4.

\section{BGD}

$9,12711-12734,2012$

Microstructure and hydraulic properties of biological soil crusts

T. Fischer et al.

Title Page

Abstract

Introduction

Conclusions

References

Tables

Figures

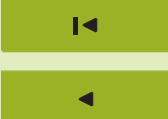

$\rightarrow 1$

Back

$>$

Close

\section{Full Screen / Esc}

Printer-friendly Version

Interactive Discussion 

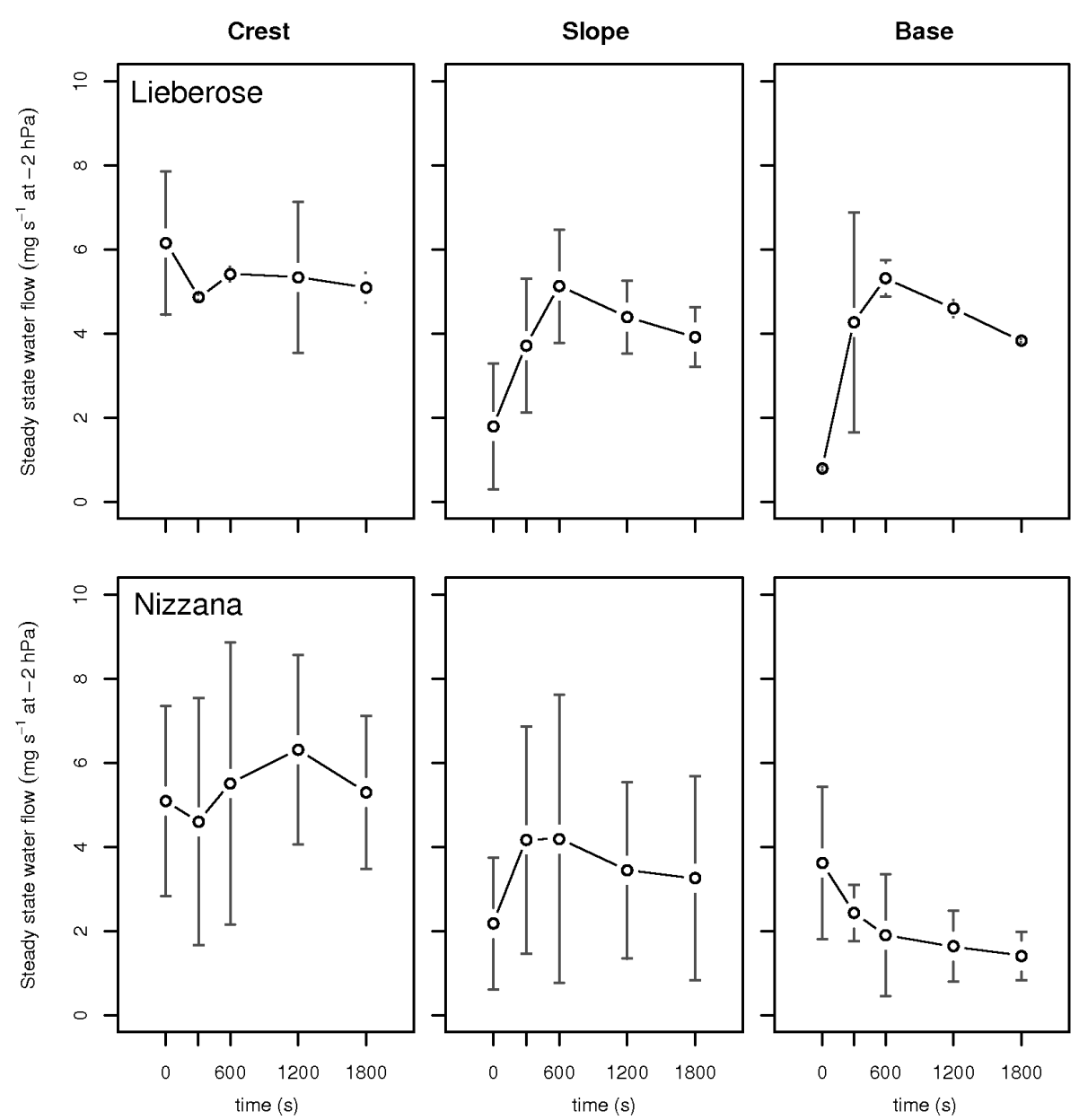

\section{BGD}

9, 12711-12734, 2012

Microstructure and hydraulic properties of biological soil crusts

T. Fischer et al.

Title Page

Abstract

Introduction

Conclusions

References

Tables

Figures

14

4

Back

Close

\section{Full Screen / Esc}

Printer-friendly Version

Fig. 6. Infiltration kinetics, error bars indicate $95 \%$ confidence intervals. 


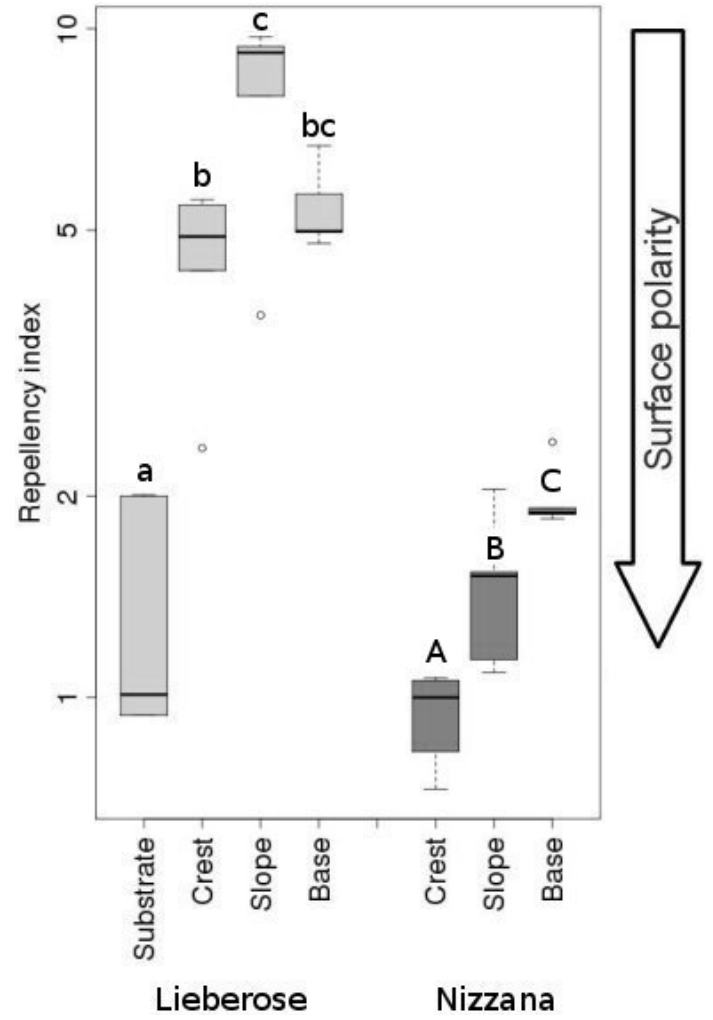

Fig. 7. Repellency indices of the BSC surface in Lieberose and in Nizzana. Non crusted substrate was used for reference in Lieberose. Identical lower or upper case letters indicate nonsignificant ranges for Lieberose and Nizzana, respectively (Tukey HSD, $p<0.05$ ). The Nizzana samples did not differ significantly from the Lieberose substrate (multiple Behrens-Fisher-Test, $p=0.86,0.97$ and 0.90 for the Nizzana dune crest, slope and base, respectively).

\section{BGD}

$9,12711-12734,2012$

Microstructure and hydraulic properties of biological soil crusts

T. Fischer et al.

\section{Title Page}

\section{Abstract}

Introduction

Conclusions

References

Tables

Figures

14

4

Back

\section{Full Screen / Esc}

Printer-friendly Version

Interactive Discussion 


\section{BGD}

9, 12711-12734, 2012

Water holding capacity ( $p F>1.8$ )

$$
\begin{aligned}
40 \%-\square & \begin{array}{l}
\text { Substrate } \\
\text { only } \\
\\
\text { Substrate + } \\
\text { BSC }
\end{array}
\end{aligned}
$$
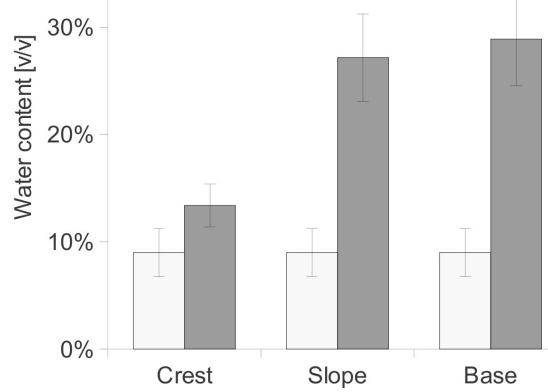

Lieberose
Water holding capacity $(\mathrm{pF}>1.8)$

$$
\begin{array}{c|c}
40 \%-\square & \begin{array}{l}
\text { Substrate only } \\
\square \\
\text { Substrate + } \\
\text { BSC }
\end{array}
\end{array}
$$$$
\text { - silt+clay }
$$

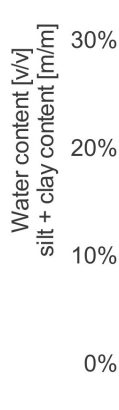

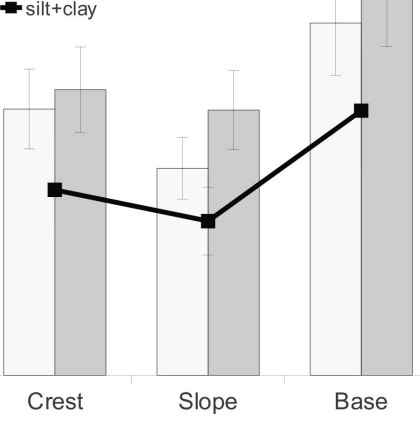

Nizzana

Fig. 8. Water holding capacities $(\mathrm{pF}>1.8$ ) of the underlying substrate and the crusted topsoils, silt and clay content of the substrate in Nizzana. Error bars indicate $95 \%$ confidence intervals. Extra water holding capacity induced by BSCs was significantly higher compared with the substrate WHC at the dune slope and base in Lieberose $(t$-Test, $p<0.05)$, but differed insignificantly for all other samples.

\section{Microstructure and hydraulic properties of biological soil crusts}

T. Fischer et al.

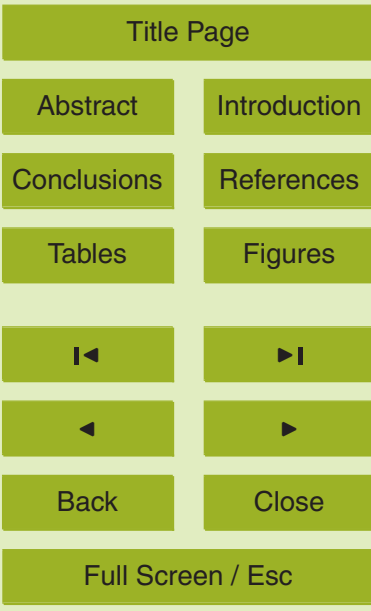

Printer-friendly Version

Interactive Discussion 


\section{BGD}

9, 12711-12734, 2012

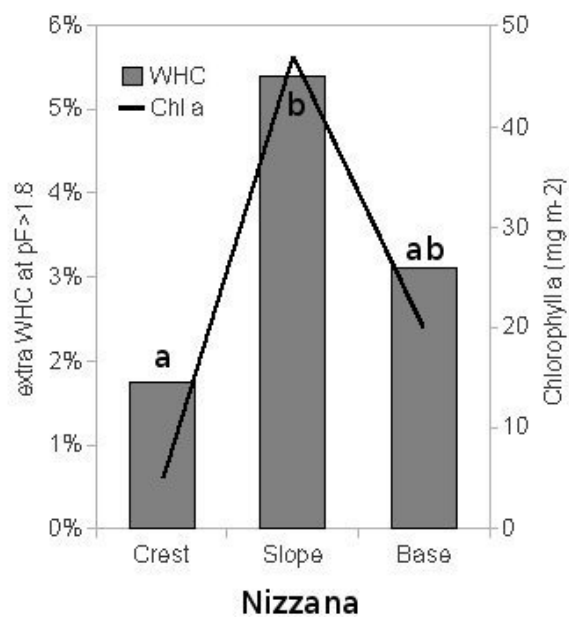

\section{Microstructure and hydraulic properties of biological soil crusts}

Fig. 9. BSC borne extra water holding capacity; Chlorophyll a concentrations (Lieberose: Fischer et al., 2010, Nizzana: Veste et al., 2001b). Identical lower and upper case letters indicate non-significant ranges of extra water holding capacity and chlorophyll a concentration, respec-

tively (Tukey HSD, $p<0.05$ ).

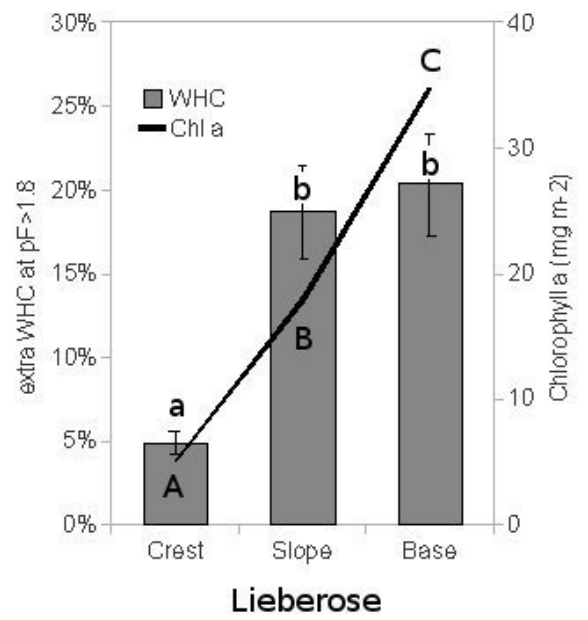

T. Fischer et al.

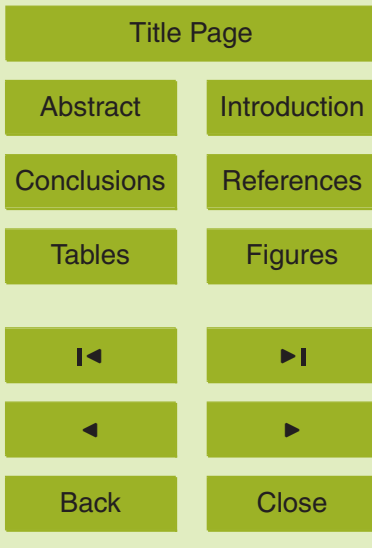

Full Screen / Esc

Printer-friendly Version

Interactive Discussion 